\title{
Infraethics-on the Conditions of Possibility of Morality
}

\author{
Luciano Floridi ${ }^{1}$
}

Published online: 30 October 2017

(C) Springer Science+Business Media B.V. 2017

It is a sign of our times that, when politicians speak of infrastructure nowadays, they often have in mind information and communication technologies (ICTs). They are not wrong. From success in business to cyber-conflicts, what makes contemporary societies work depends increasingly on bits rather than atoms. Depending on their digital infrastructures, societies may grow and prosper. And it is their ICTs that often represent one of their weakest sides, in terms of cyber security. We know all this. What is less obvious, and philosophically more interesting, is that ICTs also seem to have unveiled a new sort of equation.

Consider the unprecedented emphasis that ICTs place on crucial phenomena such as accountability, intellectual property right, neutrality, openness, privacy, transparency, and trust. These are probably better understood in terms of a platform or infrastructure of social norms, expectations and rules that is there to facilitate or hinder the moral or immoral behaviour of the agents involved. By placing at the core of our life our informational interactions so significantly, ICTs have uncovered something that, of course, has always been there, but less visibly so in the past: the fact that moral behaviour is also a matter of "ethical infrastructure", or what I have simply called infraethics.

The idea of an infraethics is simple, but the following "new equation" may help to clarify it further. In the same way as business and administration systems, in economically mature societies, increasingly require physical infrastructures (transport, communication, services etc.) to succeed, likewise human interactions, in informationally mature societies, increasingly require an infraethics to flourish. The equation is a bit more than just an analogy between infrastructure and infraethics. When economists and political scientists speak of a "failed state", they may refer to the failure of a state-as-astructure to fulfil its basic roles, such as exercising control over its borders, collecting taxes, enforcing laws, administering justice, providing schooling and so forth. Or they may refer to the collapse of a state-as-an-infrastructure or environment, which makes

Luciano Floridi

luciano.floridi@oii.ox.ac.uk

1 Oxford Internet Institute, University of Oxford, 1 St Giles, Oxford OX1 3JS, UK 
possible and fosters the right sort of social interactions. This means that they may be referring to the collapse of a substratum of default, accepted ways of living together in terms of economic, political and social conditions, such as the rule of law, respect for civil rights, a sense of political community, civilised dialogue among differentlyminded people, ways to reach peaceful resolutions of tensions and so forth. All these expectations, attitudes, rules, norms and practices, in short, such an implicit "sociopolitical infrastructure", which one may take for granted, provides a vital ingredient for the success of any complex society. It plays a vital role in human interactions, comparable to the one that we are now accustomed to attributing to physical infrastructures in economics.

The idea of an infraethics can be misleading because, despite the economic analogy, an infraethics should not be understood in terms of Marxist theory, as if it were a mere update of the old "base and superstructure" idea. The elements in question are entirely different. We are dealing with immoral/moral actions and not-yet-ethical facilitators of such immoral/moral actions. Nor should infraethics be understood, conceptually, in terms of a kind of second-order or metaethical discourse about ethics because it is rather the not-yet-ethical framework that can facilitate or hinder evaluations, decisions, actions, or situations, which are then moral or immoral. At the same time, it would also be wrong to think that an infraethics is either ethically neutral or simply has an ethical dual-use, because its dual-use is always oriented. If it were just neutral, this would mean that an infraethics would not affect either ethical or unethical behaviour, a mere logical possibility that is utterly unrealistic. In philosophy of technology, it is now commonly agreed that design — in any context, society included — is never ethically neutral but always embeds some values, whether implicitly or implicitly. Yet this does not mean that an infraethics is simply dual-use, as if it could both facilitate and hinder morally good as well as evil behaviour in equal degree, depending on other external factors. The textbook example is the knife that can save a life or murder someone. And the trivial comment is that its use and hence moral evaluation depends on the circumstances. This is true, but insufficiently perceptive because not all knives are born equal. The very short, blunt and round knife that an airline provides to spread butter has a dual-use hugely oriented to fulfil a purpose that the butcher knife can also fulfil, but much less easily. A bayonet has a dual-use only theoretically because it is designed to kill a human being, not to cut the bread. Likewise, every infraethics may be dual-use only in principle: in fact, if it is a good infraethics, it means that it is oriented towards facilitating the occurrence of what is morally good. At its best, an infraethics is the grease that lubricates the moral mechanism in the right way and successfully. So, it is easy to mistake the infraethical for the ethical because whatever helps goodness to flourish or evil to take roots, it partakes of their nature.

Any complex society-be this the City of Man or the City of God to put it in Augustinian terms - has an implicit infraethics, which can be more or less morally successful, and more or less evil-unfriendly. Theoretically, even a society of angels, that is, of impeccably good moral agents, needs infraethical rules for coordination and collaboration. Thus, James Madison was partly mistaken when he famously wrote that

If men were angels, no government would be necessary. (The Federalist No. 51, 1788). 
He was partly mistaken because he had a merely negative anthropology in mind - the one so well-articulated and advertised by Thomas Hobbes in his Leviathan and De Cive ("homo homini lupus"), and not revised nor criticised by John Locke- and an atomistic view of society as a mere aggregate of individuals. Yet, even a society of angels would still need an infraethics to coordinate its good deeds, set common goals, evaluate the degree of success in pursuing them and rectify the course of actions as a group, if necessary, because "good" can always be "better". A "we the people" is not equivalent to a mere "we, the you and I". There is a moral goodness that is entirely social and does not merely emerge from individual moral goodness because goodness is also a matter of ambitious agency: what "we the people" can do and hope to achieve together, as opposed to what you and I can ever do individually. And because evil is also a matter of opportunity costs, since, without overall governance, the angels will miss performing many good deeds available only to them as a group. Angels still need an infraethics to organise a party or push together a car that is not starting.

I wrote above that I take Madison to be only "partly" mistaken because that sentence should be read within its context, which states that:

If men were angels, no government would be necessary. If angels were to govern men, neither external nor internal controls on government would be necessary. (The Federalist No. 51, 1788, my italics).

The part in italics shows that Madison was referring to the need to structure the government with checks and balances (external and internal controls), and so one may read him more charitably as saying not that any government, or any infraethics, would be unnecessary - as stated in the first sentence - but rather one designed on the basis of an angelic anthropology. That is, he might be interpreted as arguing not that rules for coordination would be unnecessary, but that special constrains on the applications of such rule would be, if all men were angels, because those governing and those governed would behave according to the proper application of the rules all the time. With an analogy, he might be read as saying that, if all men were angels we would still need driving rules to coordinate driving behaviours, but no police to enforce them.

Insofar as Madison was mistaken - the first sentence of the quotation above definitely is, and it is often interpreted as meaning what I took it to mean above, by itselfit would also be wrong to dismiss the crucial importance of an infraethics from a more anarchist perspective. In this case, the reasoning shares the premises and draws a different conclusion: if men were angels they would need no government, but men (sometimes) are angels, and so (sometimes) they do not need government. The spontaneous emergence of the morally good is wrongly assumed as uncontroversial, by both parties. Yet, the truth is that without an infraethics to begin with, and then the issuing good governance, little moral good can be achieved individually. A multiagent system like a whole society needs its own organisation and governance.

If we now return to the oriented dual-use of an infraethics, one may argue that a society of Nazi fanatics could rely on high levels of trust, respect, reliability, loyalty, privacy and transparency, and even freedom of expression, openness and fair competition, without being for this any less evil. Clearly, what we want is not just the successful facilitations and constraints provided by the right infraethics, but also the coherent combination between them and morally good values (the right axiology), such as civil rights. This 
is why a balance between security and privacy, for example, is so difficult to achieve, unless we clarify first whether we are dealing with a tension within ethics (security and privacy as moral rights), within infraethics (both are understood as not-yet-ethical facilitators), or between infraethics (security) and ethics (privacy), as I suspect.

The right sort of infraethics is there to support the right sort of axiology. Designing it, maintaining it and keeping it updated is one of the crucial challenges for our information society. It is one of the reasons why our age is the age of design. Clearly, when talking about infrastructures, politicians have more on their plates than just networks of bits and atoms. 